\title{
An Inquiry into The Development of the Self-Conscious Emotions of Shame and Guilt in Primary School Students: The Role of Parenting Dimensions, Child's Mood, and Self-Concept
}

\author{
Marziye SalehifardFard $^{1}$, Faride Sadat Hoseini2 ${ }^{2}$, Yosof Dehghani ${ }^{2}$
}

1. M.A. student of Educational Psychology, Department of Psychology, Coll. of Literature \& Humanities, Persian Gulf University, Bushehr, Iran.

2. Assistant Professor of Psychology of Persian Gulf University, Department of Psychology, Coll. of Literature \& Humanities, Persian Gulf University, Bushehr, Iran.

* Corresponding author's Email: fhoseini@pgu.ac.ir

\begin{abstract}
Self-conscious emotions play an important role in the health and adjustment of children. They are evoked by self-reflection and self-assessment. Shame and guilt are among the self-conscious emotions that need to be considered from early childhood; the purpose of the present study is to investigate the development of self-conscious emotions of shame and guilt and the role of parenting dimensions, and child's mood and self-concept in predicting these emotions. The moderating role of age is also explored in this regard. The statistical population of the present study includes all primary school students of Jam and their families. From the given secondary schools, four classes are selected from the 3rd, 4th, 5th and 6th grades through cluster random sampling. For each grade, 50 subjects are selected that counted up to a total of 200 students and their families. The families complete the Malhotra Temperament Scale (MTS), and the Alabama parenting questionnaire. The students complete the Test of Self-conscious Affects for children (TOSCA-C), and Piers-Harissis Self-conscious Scale for Children. To test the hypotheses, descriptive and inferential analysis including mean, standard deviation and multiple regression analysis are used. The results show that parenting and mood variables significantly predicted self-conscious emotions of shame and guilty. The relationships between the predictor variables, and the dependent variables partially varied across age are indicated as well.
\end{abstract}

Keywords: Self-conscious emotions, shame, guilt, mood, self- concept, parenting styles

\section{Introduction}

Emotional development is a long process that starts in childhood and continues into adulthood. While at the outset of this prolonged process only primary emotions such as joy, anger, sadness, and fear are recognized, more complex emotions like surprise, admiration, embarrassment, guilt, shame, pride, and empathy start to emerge and develop later in life (Williams, 1990, cited in Izard (1992). A part of human emotions is called conscious emotions as they help people successfully navigate social environments. This group of emotions enable people to correct their moral and social transgressions and to maintain appropriate social behaviors (J. P. E. Tangney \& Tracy, 2012).

The concepts of shame and guilt, in particular, are such conscious emotions that develops as a result of evaluating one's actions and behaviors. As put forward by Miceli and Castelfranchi (2018), these two emotions are 'self-critical' concepts that emerge in different forms. The emotion of shame emerges when an individual fails in showing a social action according to accepted norms and criteria (M Lewis, 1992). The emotion of guilt likewise emerges as a result of evaluating one's actions in relation to legitimized social norms, objectives, and standards. In the emotion of guilt, however, the negative consequences of the self-blame cycle are activated, the motivations for compensating increase, and the incentives for preventing its recurrence in the future strengthen (Thompson, Sharp, \& Alexander, 2008). While guilt is conceived to be a normal moral emotion, the emotion of shame is identified to be an 
abnormal negative one. In this comparison, the term 'abnormal' signify that the issues of responsibility and compensation are not emphasized in the emotion of shame. In fact, people show cycles of shame mostly due to a perceived mismatch between their real selves, and their ideal selves. More clearly, shame is identified to be an unpleasant emotion that refers to an individual's self-assessment of inadequacy in reference to self-centered ideal standards. People are likely to feel ashamed either because of a set of defects such as ugliness, for which they are not responsible, or some mistakes that they are responsible for. However, in neither cases they emphasize the issues of responsibility, but the frustrating fact that their flaws are socially recognized.

Three cognitive skills are required for the development of conscious emotions such as shame and guilt. The first of these requirements is a capacity for stable self-awareness and self-representation that develops in infants between 18 to 24 months of age (M Lewis, 2008). The second requirement is an awareness of the fact that there are certain rules and standards prescribing appropriate social behavior (Sloan, 2012). Finally, children need to be aware that other people have expectations, and evaluate them for their behaviors. Although primary emotions such as fear, anger, and pleasure appear in the first year of life, self-awareness / reflection. the mental representation of the 'I' by M Lewis (2008) occurs in the next half of the second year of life when the first conscious emotions form. This remark is consistent with the research, showing that early representations of guilt, shame, and pride are at the age of three (Barrett, 1995).

As suggested by theories of emotional development, the experience, expression, and regulation of emotions can vary from one child to another as a result of the interaction of diverse social and individual factors (Mills, Arbeau, Lall, \& De Jaeger, 2010). Parenting styles are identified to be one of social factors affecting children's emotional development. Parents and caregivers contribute to the development of children's self-concious emotions through recognizing their feelings and providing special encouragement and prasise for their efforts (Frankel, Umemura, Jacobvitz, \& Hazen, 2015). In practice, the influences of parents on their children's emotional growth is not only through general parenting styles, but also through specific parenting activities such as imitating, educating, and resposnidng to children's behaviors (Mills et al., 2010). Thus, parenting styles can raise positive and/or negative consequences for children's experiecne of shame and guilt. For instance, 'authoritarian parenting' is attributed with negative behavioral consequences and lower levels of emotional regulation. 'authoritative parenting' is more associated with positive transformational consequences of emotional self-awareness, and 'casual parenting' is identified to result in the prevalence of emotional disorders (Diaz, 2005). Gallagher and Cartwright-Hatton (2008) further report positive relationships between over-reactive punitive and severe parenting style and anxiety. Kelley, Brownell, and Campbell (2000) likewise show how negative parenting style and negative evaluation of children's activities result in the development of feelings of shame. In a longitudinal study of girls, Mills (2003) reports that the use of authoritarian parenting style for three-year-old children is associated with more shame in children at age five. More recently, the results of a study by Mintz, Etengoff, and Grysman (2017) suggest that the adaptive form of guilt is associated with positive parenting style, but negative self-esteem in shame is associated with negative parenting style, even between the ages of 18 and 21. The longitudinal study of Parisette-Sparks, Bufferd, and Klein (2017) further indicate that careless parenting style at age three predicts the shame and guilt of the child at age six. There are some scholarly accounts on the relationships between parenting styles and emotions of shame and guilt (Hashemi, Dortaj, Sadipour, \& Asadzadeh, 2018).

Regarding individual's factors, one of the basic prerequisites for experiencing shame and guilt by children is self-awareness or self-knwoledge ( $\underline{M}$ Lewis, 2008), which requires an advanced level of 
cognitive function (Michael Lewis \& Sullivan, 2005). Children's self-concept can be noted as one of the individual factors influencing their preschool emotional development. Children's awareness of their abilities for doing things successfully can help to enhance and regulate their emotions (Luyten, Fontaine, \& Corveleyn, 2002). In contrast, the children who have little exoerience of success, may percive their abilities negatively and face recurrent cycles of negative self-conscious emotions such as shame and guilt. In the same line, Gilbert (2000) proposes that shame is experienced when an individual negatively evaluates their social position. In addition, Crocker et al. (2014) find a positive relationship between self-concept and the experience of shame and guilt. When people perceive themselves from the eyes of others and think that others have negative views about their behaviors, they feel ashamed or guilty (Leary, 2004). These findings generally signify that the emotion of shame is the emotion of selfawareness that is evoked by self-reflection and self-evaluation (J. P. Tangney, 2003).

Mood is argued to be one further individual factor influencing children's self-conscious emotions (Lagattuta \& Thompson, 2007). This construct is often identified as an early sign of personality as a 'personal style', determining the ways children approach and react to the world. In order to provide a solid definition of this construct, researchers have underscored diverse child's characteristics such as level of activity, adaptation to daily routines, speed of adaptation to changes, ways of reacting to new situations, irritability, intensity of reaction, and sensitivity to what is happening around them. Accordingly, children are divided into the three mood types of easy, difficult, and slow. One of the variables associated with mood is behavioral inhibition, which has attracted too much scholarly attention. It is understood in terms of low arousal threshold, feelings of fear or anxiety, and inhibition of response to new, challenging, intense or sudden events (Mills et al., 2010). The children with high behavioral inhibition have negative self-perceived behaviors (M Lewis, 1992). The findings of Mills et al. (2010) also show an increase in shame from preschool to primary school due to low mood inhibition and high maternal shame. In the same manner, Chao, Cheng, and Chiou (2011) show that shame is related to an individual's desire to avoid passivity and to have active participation in social relationships. The results of Belsky, Domitrovich, and Crnic (1997) further report that the 'easy' type of mood is not related with shame and pride (Muris, Meesters, Bouwman, \& Notermans, 2015). However indicated shame and guilt are positively and significantly related to behavioral inhibition and anxiety disorder.

Against this backdrop, this study is an attempt to explore the role of parenting styles, self-concept, and mood on the self-conscous emotions of a group of Iranin primary school students. Despite the critical roles of parenting styles, self-concept, and mood in the development of self-concious emotions, to our knwoledge, no scholarly account has explored their effectivness among primary school students. The dire need for considering intercultural differences further underscores the replication of previous studies in Iranian essay. In response to these shortcomings, the present study aims to explore how parenting styles, self-concept, and mood could predict the self-concious emotion of shame and guilt among a group of Iranian primary school students, and to unravel the developmental trend of change in the given emotions based on the three predicting variables.

\section{Material and Methods}

Research design:The study has a descriptive-correlational research design. The three constructs of parenting styles, self-concept, and mood are predicting variables, and the self-cncious emotions of shame and guilt are considered as dependent variables of the study.

Population and sample: The population of the study are all the primary school students of Jam, a southern city of Iran, during the 96-97 academic year. According to the data from the Statistics and Information Technology Depatment affiliated with the Office of Education in Jam, 4756 students were 
studying in Jam's primary schools in the given academic year. Random cluster sampling is used to recruit the sample to be representative of the features of the study population. In so doing, first, 10 out of 15 primary schools are randomly selected to narrow down the recruitment. In order to further narrow down the selection, six primary schools ( 3 girls' schools, and 3 boys' schools) were randomly selected from the 10 schools. In view of the fact that the existing research instrumnets are suitable for the children aged 9 to 11, only the third-, fourth-, fifth-, and sixth-graders are included in the study. There are three to five classes of each grade in specified schools. Four classes for girls and four others for boys are then randomly selected to further narrow down the sample. Finally, 50 students from each grade are recruited to be included in the sample that consisted of a total of 200 students.

Instrumnets: The four instruments of Malhotra Temperament Scale (MTS), Piers-Harissis Children's Self-Concept Scale, The Alabama Parenting Questionnaire (parent form), and Test of Self-conscious Affects for Children (TOSCA-C) are used to collect data on the sample's mood, self-concept, parenting styles, and self-conscious emotions of guilt and shame.

Malhotra Temperament Scale (MTS: This scale is developed by Savita Malhotra and Anil Malhotra in 1998 to measure mood. It has 45 5-point Likert-type items that examine five subscales of sociability, emotionality, energy score, attentivity, and rhythmicity. Malhotra (1988) reports a validity coefficient for the scale through comparing the results of their factor analysis with previous studies built upon factor analysis. The construct validity of the measure is determined through diagnostic function, which show significant differences between the children with and without emotional disorders. The construct validity of the scale is tested in a larger sample of 220 children with emotional disorders, 110 children with mental retardation, and 290 normal children. In the present study, the range of Cronbach's alpha coefficients for the dimensions of the instrument is between.40 and.66.

Piers-Harissis Children's Self-concept Scale: This scale with 80 items is developed by Pierce-Harris in 1969 for measuring the construct of self-concept among children and adolescents. Its administration provides a total score for self-concept, and scores for the six dimensions of behavioral adjustment, intellectual and school status, physical appearance, lack of anxiety, social acceptance (popularity), and happiness. Its test-retest, and split-half indices of reliability based on an administration to a random sample of 1060 people are found to range from .74 to .88 (Saatchi, Kamkari, \& Askarian, 2010). Asadi (1995) further reports an internal consistency of .92 for the instrument. In the present study, the range of Cronbach's alpha coefficients for the six dimensions is found to be between .25 and .74 .

The Alabama Parenting Questionnaire (parent form): This instrument that includes 42 self-report items is developed by Frick (1991) to measure parenting styles on the five dimensions of parental involvement (with children), poor supervision/monitoring, positive parenting, inconsistent discipline, and corporal punishment. Robert (2009) reports that Cronbach's alpha coefficients for the dimensions of the instrument range from .40 to $.84 ; .84$ for parental involvement, .54 for positive parenting, .55 for inconsistent discipline, .64 for poor supervision/monitoring, and .40 for corporal punishment. The construct validity of this measure is assessed using confirmatory factor analysis that supported the 5factor structure of the scale. Robert (2009) further reported that the use of the Alabama Parenting Questionnaire can properly predict children's behaviors. Nazari, Kakavand, and Mashhadi Farahani (2015) report on Cronbach's alpha coefficients of the instrument ranged from .50 to .81 , namely, .67 for parental involvement, .81 for positive parenting, .50 for inconsistent discipline, .58 for poor supervision/monitoring, and .53 for corporal punishment. In the present study, the range of Cronbach's alpha coefficients for the five dimensions of the scale was between .26 and .65 .

Test of Self-conscious Affects for Children (TOSCA-C): This test is a self-report measurement tool, consisting of 15 scenarios (10 negative and 5 positive) designed for use by children aged 8-12 years. 
Each scenario consists of a story, followed by 4 or 5 responses measuring the feelings of guilt-proneness, shame-proneness, externalization, detachment, alpha pride, and beta pride. Only the responses for the subscales of guilt-proneness and shame-proneness are included in the analysis of the present study. Responses are scored on a 5-point Likert scale ranging from completely incorrect (1) to completely correct (5). The subscale of guilt is reported to have appropriate intrinsic validity, test-retest reliability, dissociative validity, and predictive convergence (Tilghman-Osborne, 2011). Tilghman-Osborne (2011) reports a reliability index of.90 for the subscale of guilt-proneness. Abbasi, Hosseini, and Golestane (2017) further report appropriate rates of validity and reliability for the instrument. In the present study, the range of Cronbach's alpha coefficients for the dimensions of shame-proneness and guilt-proneness is between .61 and .62 .

Data analysis: Descriptive and inferential statistics including mean, standard deviation, and multiple regression are used to analyze the data. All the data analysis is performed using SPSS-24 statistical software.

\section{Results}

The first table illustrates mean and standard deviation for all the subscales of the four research instruments.

Table 1. Descriptive statistics for the research variables.

\begin{tabular}{|c|c|c|c|c|c|c|c|c|c|}
\hline \multirow[t]{2}{*}{ Scales and variables } & \multicolumn{3}{|l|}{ Males } & \multicolumn{3}{|c|}{ Females } & \multicolumn{3}{|c|}{ Whole } \\
\hline & Mean & SD & $\mathbf{N}$ & Mean & SD & $\mathbf{N}$ & Mean & SD & $\mathbf{N}$ \\
\hline \multicolumn{10}{|l|}{ MTS } \\
\hline Sociability & 51.04 & 6.58 & 79 & 48.94 & 7.45 & 115 & 49.79 & 7.16 & 194 \\
\hline Emotionality & 34.61 & 4.71 & 80 & 33.86 & 6.53 & 118 & 34.16 & 5.86 & 198 \\
\hline Energy score & 37.67 & 5.12 & 79 & 36.83 & 5.37 & 118 & 37.17 & 5.27 & 197 \\
\hline Attentivity & 17.33 & 3.21 & 80 & 16.90 & 3.47 & 118 & 17.07 & 3.36 & 198 \\
\hline Rhythmicity & 16.80 & 2.97 & 79 & 15.86 & 3.24 & 118 & 16.24 & 3.16 & 197 \\
\hline \multicolumn{10}{|c|}{ The Alabama Parenting Questionnaire } \\
\hline Positive parenting & 24.14 & 3.13 & 77 & 23.93 & 3.32 & 115 & 24.02 & 3.24 & 192 \\
\hline Poor supervision/monitoring & 20.69 & 5.35 & 75 & 20.15 & 5.84 & 108 & 20.37 & 5.64 & 183 \\
\hline Inconsistent discipline & 17.97 & 2.90 & 79 & 18.18 & 2.56 & 114 & 18.10 & 2.70 & 193 \\
\hline Corporal punishment & 6.73 & 2.35 & 77 & 6.74 & 2.00 & 117 & 6.74 & 2.14 & 194 \\
\hline Parental involvement & 36.26 & 3.71 & 77 & 35.31 & 4.60 & 111 & 35.70 & 4.27 & 188 \\
\hline \multicolumn{10}{|c|}{ Piers-Harissis Self-conscious Scale } \\
\hline Behavioral adjustment & 21.48 & 4.99 & 71 & 22.41 & 5.06 & 104 & 22.03 & 5.04 & 175 \\
\hline Intellectual and school status & 23.67 & 5.27 & 78 & 23.60 & 5.87 & 110 & 23.63 & 5.61 & 188 \\
\hline Physical appearance & 20.78 & 3.83 & 80 & 20.18 & 4.84 & 111 & 20.43 & 4.44 & 191 \\
\hline Lack of anxiety & 15.39 & 3.98 & 80 & 15.70 & 4.29 & 115 & 15.57 & 4.16 & 195 \\
\hline Social acceptance (popularity) & 12.99 & 3.62 & 77 & 13.57 & 3.84 & 102 & 13.32 & 3.75 & 179 \\
\hline Happiness & 10.75 & 3.15 & 80 & 11.55 & 2.90 & 113 & 11.22 & 3.03 & 193 \\
\hline \multicolumn{10}{|l|}{ TOSCA-C } \\
\hline Guilt-proneness & 52.66 & 7.79 & 80 & 53.21 & 7.88 & 117 & 52.99 & 7.83 & 197 \\
\hline Shame-proneness & 43.95 & 7.68 & 77 & 44.63 & 7.43 & 116 & 44.36 & 7.52 & 193 \\
\hline
\end{tabular}

As the results of Kolmogorov-Smirnov test of nomality $\left(\mathrm{KM}_{=} .05, \mathrm{Sig} .=.2\right)$ show that the data is normalily distributed, hierarchical regression is used to analyze the role of parenting styles in predicting the sample's self-concious emotion of shame as the moderating variable are added to the model. 
Table 2. The results of hierarchical regression for the interaction of parenting styles and age in predicting shame

\begin{tabular}{|c|c|c|c|c|c|c|}
\hline Predictors & B & B & $\mathbf{R}$ & $\mathbf{R}^{2}$ & $\mathbf{T}$ & $p$ \\
\hline Positive parenting & -.21 & -.09 & & & -.89 & .38 \\
\hline Poor supervision/monitoring & .55 & .40 & & & 4.57 & $.00 *$ \\
\hline Inconsistent discipline & .35 & .13 & & & 1.66 & .10 \\
\hline Corporal punishment & -.38 & -.11 & & & -1.33 & .18 \\
\hline Parental involvement & -.03 & -.01 & & & -.15 & .88 \\
\hline Age group & 3.81 & .25 & .27 & .52 & 3.48 & .00 \\
\hline Positive parenting $*$ age group & .35 & .61 & & & .72 & .47 \\
\hline Poor supervision/monitoring $*$ age group & -.02 & -.04 & & & -.09 & .93 \\
\hline Inconsistent discipline $*$ age group & .89 & 1.12 & & & 2.10 & $.04 *$ \\
\hline Corporal punishment $*$ age group & .59 & .36 & & & 1.02 & .31 \\
\hline Parental involvement $*$ age group & .18 & .45 & & & .46 & .64 \\
\hline
\end{tabular}

As shown in table 2, from among the six dimentions of parenting, only the subscale of poor supervision/monotoring is a positive and significant predictor of shame $\left(\mathrm{P}_{=} .00, \beta_{=} .40\right)$. Put differently, poor supervision/monitoring is associated with an increase in children's shame. Age is also found to be a positive predictor of shame $\left(\mathrm{P}_{=} .001, \beta_{=} .25\right)$, signifying that older children are scored higher on the emotion of shame. As to the interaction of parenting style and age, the results show that the interaction of inconsistent discipline and age positively predict shame $\left(P_{=} .04,12, \beta=1.12\right)$. In fact, inconsistent discipline is predictor of shame in 11- to 12-year-old students than 9- to 10-year-olds. It is further found that the predictor variables accounted for a total of 27 percent of the variance in children's shame.

Hierarchical regression investigates the role of parenting style in predicting the emotion of guilt, because the results of Kolmogorov-Smirnov test show the data is normally distributed $\left(\mathrm{KS}_{=} .04\right.$, Sig.= .2) Moreover, distribution diagrams show no evidence of nonlinearity in the relationship between the predictor and dependent variables. The value of tolerance index for the predictor is also higher than .49. In view of the fact that all the values are greater than the critical value of .1, it is argued that there are no high relationships between the variables and the assumption of nonlinearity.

Table 3. The results of hierarchical regression for the interaction of parenting styles and age in predicting guilt

\begin{tabular}{|c|c|c|c|c|c|c|}
\hline Predictors & B & B & $\mathbf{R}$ & $\mathbf{R}^{2}$ & $\mathbf{T}$ & $p$ \\
\hline Positive parenting & .20 & .08 & & & .77 & .44 \\
\hline Poor supervision/monitoring & .07 & .05 & & & .51 & .61 \\
\hline Inconsistent discipline & .66 & .23 & & & 2.85 & $.00 *$ \\
\hline Corporal punishment & -.10 & -.03 & & & -.32 & .75 \\
\hline Parental involvement & -.10 & -.05 & & & -.48 & .63 \\
\hline Age group & 4.69 & .30 & .41 & .17 & 3.95 & .00 \\
\hline Positive parenting $*$ age group & -.34 & -.56 & & & -.63 & .53 \\
\hline Poor supervision/monitoring * age group & .20 & .32 & & & .72 & .47 \\
\hline Inconsistent discipline $*$ age group & 1.11 & 1.34 & & & 2.35 & $.02 *$ \\
\hline Corporal punishment $*$ age group & -1.05 & -.63 & & & -1.68 & .09 \\
\hline Parental involvement $*$ age group & .20 & .47 & & & .47 & .64 \\
\hline
\end{tabular}

As illustrated in table 3, only the dimension of inconsistent discipline is found to be a positive and significant predictor of guilt in the sample $\left(\mathrm{P}_{=} .005, \beta_{=} .23\right)$. In other words, instability in dealing with children is associated with an increase in their guilt. Age group is also found to be a positive and significant predictor of guilt $\left(\mathrm{P}_{=} .0001, \beta_{=} .30\right)$ in which the students who are 11 and 12 years old, have higher scores in guilt compared to those who are 9 and 10 years old. The interaction of inconsistent discipline and age group is a further predictor of the emotion of guilt $\left(\mathrm{P}_{=} .20, \beta_{=}\right.$1.34). The children 
who are 11 and 12 years old had higher scores of guilt. A total of 17 percent of the variance of guilt is predicted by the predictors. The results of Kolmogorov-Smirnov test further show that the data for the role of self-concept in predicting shame is normally distributed $\left(\mathrm{KS}_{=} .06, \mathrm{Sig} .=.2\right)$. The study of graphs further proposes nonlinearity in the relationship between the predictors and the dependent variables. In addition, the value of tolerance index of the predictor variables is all higher than .31 . The assumption of nonlinearity is connected, and no high correlation between the predictors are observed, because all the values are greater than the critical value of 0.1 . Therefore, hierarchical regression is used to show how self-concept could predict the emotion of shame in the sample.

Table 4. The results of hierarchical regression for the interaction of self-concept and age in predicting shame

\begin{tabular}{|c|c|c|c|c|c|c|}
\hline Predictors & B & B & $\mathbf{R}$ & $\mathbf{R}^{2}$ & $\mathbf{T}$ & $p$ \\
\hline Behavioral adjustment & -.62 & -.43 & & & 3.59 & $.001 *$ \\
\hline Intelectual and school status & .13 & .10 & & & .80 & .43 \\
\hline Physical appearance & -.14 & -.08 & & & -.86 & .39 \\
\hline Lack of anxiety & -.17 & -.10 & & & -1.13 & .26 \\
\hline Social acceptance (popularity) & -.07 & -.04 & & & -.42 & .67 \\
\hline Happines & -.30 & -.10 & & & -1.23 & .23 \\
\hline Age group & .99 & .07 & .65 & .43 & .96 & .34 \\
\hline Behavioral adjustment $*$ age group & .37 & .60 & & & 1.09 & .28 \\
\hline Intelectual and school status & .64 & 1.28 & & & 1.99 & $.05 *$ \\
\hline Physical appearance $*$ age group & .28 & .48 & & & .84 & .40 \\
\hline Lack of anxiety $*$ age group & -.94 & -1.28 & & & -3.21 & $.001 *$ \\
\hline Social acceptance (popularity) * age group & -1.02 & -1.28 & & & -2.94 & $.001 *$ \\
\hline Happiness * age group & -.29 & -.27 & & & -.62 & .54 \\
\hline
\end{tabular}

As shown in table 4, the dimension of behavioral adjustment is found to be a negative predictor of shame $\left(\mathrm{P}_{=} .0001\right.$, Sig. $\left.=-.43\right)$. In fact, an increase in behavioral adjustment is associated with a decrease in the sample's shame. As to the interaction of self-concept and age, the results show that the interaction of intellectual and school status and age group could predict shame $(\beta=-.43, \mathrm{P}=.001)$. In other words, the students with age 11 and 12 have higher scores for intellectual and school status. The interaction of lack of anxiety with age $\left(\beta=-1.28, \mathrm{P}_{=} .001\right)$, and social acceptance with age $(\beta=-1.28, \mathrm{P}=.001)$ are further found to predict the construct of shame in the sample. Put differently, the students with age 9 and 10 had higher scores on lack of anxiety and social acceptance, compared to those aged 11 and 12. The predictor variable sin general accounted for a total of 43 percent of the variance in the sample's shame. The results of Kolmogorov-Smirnov test also show the data on the role of self-concept in predicting guilt is not normally distributed $\left(\mathrm{KS}_{=} .09\right.$, Sig. $\left.=.001\right)$. However, hierarchical regression is used to analyze the data. The examination of graphs signifies no evidence of nonlinearity in the relationship between the predictor and dependent variables. Moreover, the value of tolerance index of predictors is all higher than .31 . There are no high correlations between the predictor variables. The assumption of nonlinearity is linked as all the values get higher than the critical value of .01 . 
Table 5. The results of hierarchical regression for the interaction of self-concept and age in predicting guilt

\begin{tabular}{|c|c|c|c|c|c|c|}
\hline Predictors & B & B & $\mathbf{R}$ & $\mathbf{R}^{2}$ & $\mathbf{T}$ & $\mathbf{P}$ \\
\hline Behavioral adjustment & -.38 & -.26 & \multirow{13}{*}{.65} & \multirow{13}{*}{.43} & 2.08 & .04 \\
\hline Intelectual and school status & -.38 & -.28 & & & 2.18 & $.03 *$ \\
\hline Physical appearance & -.03 & -.02 & & & 0.19 & .85 \\
\hline Lack of anxiety & .20 & .12 & & & 1.29 & .20 \\
\hline Social acceptance (popularity) & .05 & .03 & & & .30 & .76 \\
\hline Happines & -.12 & -.04 & & & -.45 & .66 \\
\hline Age group & 2.37 & .16 & & & 2.14 & $.03 *$ \\
\hline Behavioral adjustment $*$ age group & .05 & .07 & & & .12 & .90 \\
\hline Intelectual and school status & .24 & .47 & & & 67 & .51 \\
\hline Physical appearance $*$ age group & -.19 & -.32 & & & -.51 & .61 \\
\hline Lack of anxiety $*$ age group & -.46 & -.62 & & & -1.40 & .16 \\
\hline Social acceptance (popularity) $*$ age group & .16 & .20 & & & .42 & .67 \\
\hline Happiness $*$ age group & .57 & .51 & & & 1.06 & .29 \\
\hline
\end{tabular}

As shown in table 5, the two subscales of behavioral adjustment $\left(\beta \square .24, \mathrm{P}_{=} .04\right)$, and intellectual and school status $\left(\beta \square .28, \mathrm{P}_{=} .03\right)$ are negative predictors of guilt in the sample. In other words, an increase in these two dimensions of self-concept is associated with a decrease in the emotion of guilt among the children. Neither the other dimensions of self-concept nor the interaction of self-concept predict the variance of guilt. Self-concept as the predictor variable is accounted for a total of 43 percent of the variance of guilt in the sample.

In order to investigate the role of mood in predicting the sub-conscious emotion of shame, first Kolmogorov-Smirnov test is used, which shows the data is normally distributed $\left(\mathrm{KS}_{=} .06, \mathrm{Sig} .=.08\right)$. The examination of graphs further shows no evidence that the relationship between the predictors and the dependent variables is nonlinear. In addition, the value of tolerance index of predictor variables is all higher than.52, signifying that there is no high correlation between predictor variables and the assumption of nonlinearity. These findings allow for the conduction hierarchical regression to predict how mood could predict the emotion of shame in the sample.

Table 6. The results of hierarchical regression for the interaction of mood and age in predicting shame

\begin{tabular}{|c|c|c|c|c|c|c|}
\hline Predictors & $\mathbf{B}$ & B & $\mathbf{R}$ & $\mathbf{R}^{2}$ & $\mathbf{T}$ & $p$ \\
\hline Sociability & .19 & .18 & \multirow{11}{*}{.42} & \multirow{11}{*}{.16} & 1.97 & .05 \\
\hline Emotionality & -.39 & -.30 & & & -3.34 & $.00 *$ \\
\hline Energy score & .17 & .12 & & & 1.20 & .23 \\
\hline Attentivity & .15 & .07 & & & .71 & .48 \\
\hline Rhythmicity & -.24 & -.10 & & & -1.16 & .25 \\
\hline Age group & 2.19 & .15 & & & 2.04 & .04 \\
\hline Sociability $*$ age group & .46 & 1.71 & & & 2.22 & $.03 *$ \\
\hline Emotionality * age group & .53 & 1.35 & & & 2.23 & $.03 *$ \\
\hline Energy score * age group & -.41 & -1.07 & & & -1.34 & .18 \\
\hline Attentivity $*$ age group & -.09 & -.12 & & & -.22 & .83 \\
\hline Rhythmicity * age group & -.08 & -.10 & & & -.19 & .85 \\
\hline
\end{tabular}

Finally, in order to investigate the role of mood in predicting the self-conscious emotion of guilt in the sample, first Kolmogorov-Smirnov test of normality shows that data is normally distributed $\left(\mathrm{KS}_{=} .04\right.$, Sig. = .2). The examination of distribution graphs further represents no evidence of nonlinearity in the relationship between the predictors and dependent variables. In addition, the value of tolerance index of predictors is all higher than .52. As shown in table six, from the dimensions of children's mood, sociability $\left(\beta_{=} .18, \mathrm{P}_{=} .05\right)$ and emotionality $\left(\beta_{=} .03, \mathrm{P}=.00\right)$ are the negative and significant predictors of shame. In addition, the interaction of age group with sociability $\left(\beta=1.71, P_{=} .03\right)$ and emotionality 
$\left(\beta=1.35, P_{=} .03\right)$ are found to be positive in predicting shame. In view of the fact that the dimension of emotionality is a negative predictor of shame, the relationship between the predictor and the dependent variable is explored in more detail to cast further light on the interaction. The results show that emotionality is a negative and significant predictor of children's shame only in the group of the children who are 9 to 10 years old. On the other hand, sociability is a positive and significant predictor of shame in the children who are 11 and 12 years old. The predictor variables are accounted for a total of 16 percent of the variance in the sample's shame.

Table 7. The results of hierarchical regression for the interaction of mood and age in predicting guilt

\begin{tabular}{|c|c|c|c|c|c|c|}
\hline Predictors & $\mathbf{B}$ & $\mathbf{B}$ & $\mathbf{R}$ & $\mathbf{R}^{2}$ & $\mathbf{T}$ & $p$ \\
\hline Sociability & .05 & .05 & \multirow{11}{*}{.52} & \multirow{11}{*}{.27} & .50 & .62 \\
\hline Emotionality & -.33 & -.25 & & & -2.85 & $.00 *$ \\
\hline Energy score & .15 & .11 & & & 1.09 & .28 \\
\hline Attentivity & .09 & .04 & & & .43 & .66 \\
\hline Rhythmicity & -.17 & -.07 & & & -.82 & .41 \\
\hline Age group & 4.33 & .28 & & & 4.02 & .00 \\
\hline Sociability $*$ age group & -.06 & -.21 & & & -.29 & .77 \\
\hline Emotionality $*$ age group & .45 & 1.12 & & & 1.90 & .06 \\
\hline Energy score * age group & .31 & .80 & & & 1.07 & .29 \\
\hline Attentivity $*$ age group & -.13 & -.17 & & & -.31 & .75 \\
\hline Rhythmicity * age group & -.01 & -.01 & & & -.03 & .98 \\
\hline
\end{tabular}

As shown in table 7, from among the dimensions of mood, only emotionality is a negative predictor of guilt in the sample $\left(\beta_{=} .25, \mathrm{P}_{=} .00\right)$. The interactions of mood with age group however do not predict the guilt in the sample. The predictor variables are accounted for a total 27 percent of the variance in the children's guilt.

\section{Discussion}

This study aims to investigate the developmental role of parenting style, self-concept, and mood in predicting the self-conscious emotions of shame and guilt among a group of primary school students. Hierarchical regression analysis is used to analyze the data. In this section, first, the role of parenting style, self-concept, and mood in predicting the emotion of shame based on age is discussed. Then, the data for the emotion of guilt is reviewed and discussed.

The results of regression analysis on the role of parenting style in predicting the emotion of shame show that the dimension of poor supervision/monitoring is a positive and significant predictor. The interaction of parental involvement and age is also a significant predictor of shame. Poor parental supervision connotes poor guidance, poor management, and impulsive control on children. Given that shame is a negative emotion associated with shrinkage, worthlessness, and disability (M Lewis, 1992), poor supervision lead to a rise in expediting shame by children. In the same manner, Parisette-Sparks et al. (2017) show that the careless style of parenting when children are three years old can predict the emotions of shame and guilt in higher ages. As mentioned earlier, negligent parenting is characterized by a lack of parental control and compliance with the child's wishes, which is associated with the prevalence of emotional disorders among children (Diaz, 2005). The results further show that the experience of shame by children can be predicted by their age. An increase in age results in the experience of more shame among the children. As reported by Mills et al., 2010, the rate of shame among primary school children increases as they grow up. Another piece of finding shows that the interaction of inconsistent discipline and age predict emotions. In this regard, it can be stated that 
inconsistency discipline means inconsistency in the way of dealing with the child, which predicts the emotion of shame among them. This can be attributed to the fact that the emotion of shame is the product of evaluating one's actions in relation to diverse rules, goals, and standards (M Lewis, 1992). In fact, instability in parental behavior results in higher negative self-evaluation among children. In order to create positive self-evolution among children, parents need to be consistent in setting goals and standards for their behavior.

The results of hierarchical regression on the role of self-concept in predicting the emotion of shame, with age as a moderating variable included in the model, show that the dimension of behavioral adjustment could predict the emotion of shame. It is further found that the interaction of age with intellectual and school status, lack of anxiety, and social acceptance could negatively predict the experience of shame. In explaining the negative role of behavioral adjustment in children's experience of shame, it can be stated that behavioral adjustment means children's perception of their abilities for showing appropriate behavior. The fact that positive behavioral adjustment involves a positive attitude and self-esteem towards oneself, the children with positive self-concept in terms of behavior consequently experience less shame. This further underscores the fact that the emotion of shame is a self-conscious one that is evoked by self-reflection and negative self-esteem (J. P. Tangney, 2003).. It is noteworthy that the behavioral aspect of self-concept has diverse external and visible dimensions that decreases in response to an increase in the child's age. The results also show that the interaction intellectual and school status with age is a positive predictor of shame. This means that, in the students ages 11 and 12, intellectual and school status is a stronger predictor of the emotion of shame. Also, the interaction of age with lack of anxiety, and social acceptance are found to be significant predictors of shame. Although the dimensions of lack of anxiety, and social acceptance positively predict the emotion of shame among the students of 9 and 10 years old. They are negative predictors of shame among the children who are 11 and 12 years old. However, social acceptance is not a significant predictor of shame in this age group. As the results show, self-concept is an important variable in predicting the experience of shame. Likewise, Gilbert (2000) show that shame is experienced when one evaluates one's position in a low social position. In addition, the emotion of shame is understood to be the result of a perceived difference between the real self and the ideal self. It further refers to a person's self-assessment of their inadequacy to have their own ideal standards (Miceli \& Castelfranchi, 2018).

The results of regression analysis on the role of mood in predicting the emotion of shame, with age as the moderating variable inclusion, show that only the dimensions of positive sociability predicts shame. The experience of shame is also positively predicted by the interactions of age with sociability, and emotionality. In explaining the positive role of sociability in shame, it is necessary to consider the nature of this variable. To say, this factor includes the child's mood tendency for isolation, adaptability, and response threshold. A high score on this variable indicates that the child is fully responsive, modifiable and adaptable to the environment (Malhotra, 1988). The shame is the result of a failure when one accepts responsibility for the failure and has a general focus on oneself (M Lewis, 1992). Hence, the children with mood swings are more likely to focus on self-assessment. So this type of mood can make the child more vulnerable to more shameful experiences. In this regard, J. Tangney and Dearing (2003) show that dependent children are generally prone to experience shame. On the other hand, emotionality comprises of two parts, namely, mood and stability. A high score on emotionality indicates the consistency of a positive and happy mood in the individual (Malhotra, 1988). Therefore, the children with positive and happy moods have less negative self-assessments and those with this positive mood swings experience less shame. These individuals are different from the children who have a high level of behavioral inhibition because the children with high behavioral inhibitions have more negative attributions about 
their behavior (M Lewis, 1992). In this regard, Chao et al. (2011) show that shame is associated with an individual's creative desire to avoid inactivity and active independence from social relationships. In addition, the interaction of age group with the dimensions of sociability and emotionality lead to different experiences of shame in the sample. Thus, emotionality is a negative and significant predictor of children's shame emotion only in the group of 9-, and 10-year-olds while social acceptance is a positive and significant predictor of children's shame only in the children aged 11 and 12.

Regarding emotion of guilt, the results of regression analysis on the role of parenting variables interaction with participant's age show that only the dimensions of inconsistent discipline could positively predict guilt. Age alone is also a positive predictor of guilt in the sample. In explaining the positive role of inconsistent discipline in increasing the guilt of primary school children, it can be stated that when parents are not consistent in dealing with children, children are confused in determining the do's and don'ts of moral standards. Because guilt refers to negative moral self-esteem (Miceli \& Castelfranchi, 2018), impulsive and unstable attitudes can increase guilt in children. This construct includes self-evaluation of one's actions for which they consider themselves responsible and activate the cycle of self-blaming (Thompson et al., 2008). In this regard, Gallagher and Cartwright-Hatton (2008) show that there is a positive relationship between hyperactive parenting (associated with unstable parenting style) and anxiety in children. The results also show that with an increase win age, the children's level of guilt increases. Given the importance of peers in the classroom, the increase in guilt can be explained by a greater emphasis on moral self-assessment. Self-conscious conscious emotions such as guilt arise when one perceives and evaluates oneself through the eyes of others (Leary, 2004). Moreover, the findings show that inconsistent discipline interaction and age could lead to an increase in the self-conscious emotion of guilt. Thus, parental instability creates a stronger potential for 11- to 12year-olds to experience feelings of guilt. Hence, the children at the age of 11 and 12 experience more guilt in the face of failure in front of their peers.

The results of regression analysis on the role of self-concept and age in predicting the emotion of guilt show that only the behavioral adjustment dimensions and intellectual and school status negatively predict guilt. More specifically, with an increase in the children's perception of appropriate behavior and academic performance, less guilt is predicted in their behaviors. In explaining the negative role of behavior in the experience of guilt, it can be said that an increase in the dimension of behavioral adjustment means that the child evaluates his ability as a tool for showing positive proportionate behavior (Miceli \& Castelfranchi, 2018). In the same manner, intellectual and school status includes children's cognition of their cognitive and academic abilities. Hence, the children who assess themselves as cognitively and academically capable are less likely to experience guilt. Guilt, which involves selfcriticism in that children, activate self-evaluation for the behaviors, beliefs, or characteristics (Miceli \& Castelfranchi, 2018). Likewise, Crocker et al. (2014) propose a positive relationship between apparent self-concept and the experience of shame and guilt in women. Luyten et al. (2002) also report that children develop the required abilities for managing emotions through raising awareness of their own values and abilities.

The results of regression analysis on the role of mood and age in predicting guilt show that the dimension of emotionality negatively predicted guilt. Hence, as the child's mood swings to be aroused, the child experiences less guilt. This can be attributed to the fact that emotionality is defined as having a positive and happy mood in a sustainable way (Malhotra, 1988). Therefore, a person with this positive mood can not develop a negative self-criticism that is the basis for experiencing guilt (Miceli \& Castelfranchi, 2018). As emphasized by Mills et al. (2010), in construction associated with mood, a special attention has been paid to issue of behavioral inhibition, which is identified in terms of low arousal threshold, 
mental feeling of fear or anxiety, and inhibition of response to new and challenging events. People with high emotionality have little behavioral inhibition and consequently a lower level of guilt. It is worth mentioning that age can partially explain the experience of guilt in children only through an interaction with the variables of parenting. However, age is not interacted with the dimensions of self-concept and mood in explaining the experience of guilt.

In general, the findings show that diverse parenting style, self-concept, mood, and age play a pivotal role in the experience of the self-conscious emotions of shame and guilt among primary school students. Based on the results of the present study, suggestions can be made to the officials in the office of education, psychologists and counselors of counseling centers in schools. Since the emotions of guilt and shame play an important role in the development of mental and emotional disorders, preventive programs can be prepared through considering the dimensions of parenting, self-concept and mood, and age of children. For instance, due to the critical role of sociability in the experience of shame, the children who have a sociable mood are more likely to experience it. Therefore, it is necessary to provide training with the purpose of moderating such feelings among children. Moreover, as emotionality is a negative predictor of shame and guilt, school counselors can implement programs in school to enhance this type of mood among children. In general, the experience of guilt by primary school children can be moderated and reduced through the provision of training courses aiming at increasing children's motivations, self-concept, especially in behavioral and intellectual areas. Holding workshops for enhancing parental styles in terms of consistency in supervision can equally improve children's subconscious emotions of shame and guilt. Finally, it is worthy of mentioning that one of the limitations of the study is its cross-sectional nature. A longitudinal research design can cast further light on the nature of sub-conscious emotion among children. In addition, as the study is concentrated on primary school students, its findings cannot be generalized to other age groups. Accordingly, future researchers are suggested to explore other age groups, especially preschool ones, for the predictors of shame and guilt.

Conflict of interest: The authors state no conflict of interest in the study.

Financial sponsor: The authors acknowledge that they have not received any financial support for all stages of the study, writing and publication of the paper.

Acknowledgment: We hereby appreciate all the participants of the study as well as all those participating in the implementation of this project.

\section{References}

Abbasi, N., Hosseini, F. S., \& Golestane, S. M. (2017). The role of attribution styles in self-conscious emotions of shame and guilt for elementary schools' students. Studies in Learning \& Instruction, $8(2), 1-18$.

Asadi, M. (1995). The standardization of Piers-Harissis Self-concept Scale in Kerman Province. The Research counsel of Office of Education. Unpublished. 
Barrett, K. C. (1995). A functionalist approach to shame and guilt. In J. P. Tangney \& K. W. Fischer (Eds.), Self-conscious emotions: The psychology of shame, guilt, embarrassment, and pride (pp. 2563): Guilford Press.

Belsky, J., Domitrovich, C., \& Crnic, K. (1997). Temperament and parenting antecedents of individual differences in three-year-old boys' pride and shame reactions. Child development, 68(3), 456-466.

Chao, Y.-H., Cheng, Y.-Y., \& Chiou, W.-B. (2011). The psychological consequence of experiencing shame: Self-sufficiency and mood-repair. Motivation and Emotion, 35(2), 202-210.

Crocker, P. R., Brune, S. M., Kowalski, K. C., Mack, D. E., Wilson, P. M., \& Sabiston, C. M. (2014). Body-related state shame and guilt in women: Do causal attributions mediate the influence of physical self-concept and shame and guilt proneness. Body Image, 11(1), 19-26.

Diaz, Y. (2005). Associations between parenting and child behavior problems among Latino mothers and children: University of Maryland, College Park.

Frankel, L. A., Umemura, T., Jacobvitz, D., \& Hazen, N. (2015). Marital conflict and parental responses to infant negative emotions: Relations with toddler emotional regulation. Infant behavior and development, 40, 73-83.

Frick, P. (1991). The Alabama parenting questionnaire: Unpublished rating scale. New Orleans: University of New Orleans: Department of Psychology.

Gallagher, B., \& Cartwright-Hatton, S. (2008). The relationship between parenting factors and trait anxiety: Mediating role of cognitive errors and metacognition. Journal of Anxiety Disorders, 22(4), $722-733$.

Gilbert, P. (2000). The relationship of shame, social anxiety and depression: The role of the evaluation of social rank. Clinical Psychology \& Psychotherapy: An International Journal of Theory \& Practice, 7(3), 174-189.

Hashemi, S., Dortaj, F., Sadipour, S., \& Asadzadeh, H. (2018). Structural pattern of the emotions of shame and guilt based on parents' parenting styes: the mediating role of attachment styles. Journal of applied psychology, 4(44), 475-493.

Izard, C. E. (1992). Basic emotions, relations among emotions, and emotion-cognition relations. Psychological Review, 99, 561-565.

Kelley, S. A., Brownell, C. A., \& Campbell, S. B. (2000). Mastery motivation and self-evaluative affect in toddlers: Longitudinal relations with maternal behavior. Child development, 71(4), 1061-1071.

Lagattuta, K. H., \& Thompson, R. A. (2007). The development of self-conscious emotions: Cognitive processes and social influences. . In R. W. R. J. L. Tracy, \& J. P. Tangney (Ed.), The self-conscious emotions: Theory and research (pp. 91-113): Guilford Press.

Leary, M. R. (2004). Digging deeper: The fundamental nature of" Self-conscious" emotions. Psychological Inquiry, 15(2), 129-131.

Lewis, M. (1992). Shame: The Exposed Self. . New York: The Free Press.

Lewis, M. (2008). Self-conscious emotions: Embarrassment, pride, shame, and guilt. In J. M. M. Lewis, Haviland-Jones, \& L. F. Barrett (Eds.), Handbook of emotions (pp. 742-756): The Guilford Press.

Lewis, M., \& Sullivan, M. W. (2005). The development of self-conscious emotions. Handbook of competence and motivation, 185-201.

Luyten, P., Fontaine, J. R., \& Corveleyn, J. (2002). Does the Test of Self-Conscious Affect (TOSCA) measure maladaptive aspects of guilt and adaptive aspects of shame? An empirical investigation. Personality and Individual Differences, 33(8), 1373-1387.

Malhotra, S. (1988). Manual of Malhotra's Temperament Schedule. Agra: National Psychological Corporation. 
Miceli, M., \& Castelfranchi, C. (2018). Reconsidering the differences between shame and guilt. Europe's journal of psychology, 14(3), 710.

Mills, R. S. (2003). Possible antecedents and developmental implications of shame in young girls. Infant and Child Development: An International Journal of Research and Practice, 12(4), 329-349.

Mills, R. S., Arbeau, K. A., Lall, D. I., \& De Jaeger, A. E. (2010). Parenting and child characteristics in the prediction of shame in early and middle childhood. Merrill-Palmer Quarterly (1982-), 500-528.

Mintz, G., Etengoff, C., \& Grysman, A. (2017). The relation between childhood parenting and emerging adults' experiences of shame and guilt. Journal of Child and Family Studies, 26(10), 2908-2920.

Muris, P., Meesters, C., Bouwman, L., \& Notermans, S. (2015). Relations among behavioral inhibition, shame-and guilt-proneness, and anxiety disorders symptoms in non-clinical children. Child Psychiatry \& Human Development, 46(2), 209-216.

Nazari, F., Kakavand, A. R., \& Mashhadi Farahani, M. (2015). The relationship between early incompatible schemas with mothers' parenting, and their children's externalized disorders. Journal of applied psychology, 9(2), 115-135.

Parisette-Sparks, A., Bufferd, S. J., \& Klein, D. N. (2017). Parental predictors of children's shame and guilt at age 6 in a multimethod, longitudinal study. Journal of Clinical Child \& Adolescent Psychology, 46(5), 721-731.

Robert, C. J. (2009). Parenting practices and child behavior in Mexico: A validation study of the Alabama parenting questionnaire: University of Minnesota.

Saatchi, M., Kamkari, K., \& Askarian, M. (2010). Psychological tests. Tehran: Virayesh Publication.

Sloan, G. (2012). Emergent Literacy: Children's Books from 0 to 3. Children's Literature Association Quarterly, 37(4), 507-509.

Tangney, J., \& Dearing, R. L. (2003). Shame and guilt: Guilford Press.

Tangney, J. P. (2003). Self-relevant emotions. In M. R. L. J. P. Tangney (Ed.), Handbook of self and identity (pp. 384-400): The Guilford Press.

Tangney, J. P. E., \& Tracy, J. L. (2012). Self-conscious emotions. In M. R. Leary \& J. P. Tangney (Eds.), Handbook of self and identity. New York: Guilford Press.

Thompson, T., Sharp, J., \& Alexander, J. (2008). Assessing the psychometric properties of a scenariobased measure of achievement guilt and shame. Educational Psychology, 28(4), 373-395.

Tilghman-Osborne, C. (2011). Inappropriate and excessive guilt: Measure validation and developmental findings in the relation to depression across development: Vanderbilt University. 